\title{
O TRABALHO COLABORATIVO E O DESENVOLVIMENTO PROFISSIONAL DE UM GRUPO DE PROFESSORES DOS ANOS INICIAIS: olhar para resolução de problemas
}

\author{
THE COLLABORATIVE WORK AND THE PROFESSIONAL DEVELOPMENT OF \\ A GROUP OF TEACHERS OF THE INITIAL YEARS: look at resolvin solving \\ EL TRABAJO COLABORADOR Y EL DESARROLLO
PROFESIONAL DE UN EQUIPO DE PROFESORES DE LOS AÑOS
INICIALES: la mirada para la resolución de problemas
}

Sandra Alves de Oliveira Professora Mestre do Departamento de Educação de Guanambi - Campus XII da Universidade do Estado da Bahia (UNEB). Guanambi-BA, Brasil. saoliveira@uneb.br

Carmen Lucia Brancaglion Passos Professora Doutora do Programa de Pós-Graduação em Educação da Universidade Federal de São Carlos (UFSCar). São Paulo-SP, Brasil. carmen@ufscar.br

\begin{abstract}
Resumo: Este artigo é parte de uma pesquisa de natureza descritiva e interpretativa, que investigou desafios, dilemas, saberes e aprendizagens que emergem no processo de formação continuada de professores dos anos iniciais ao estudarem e utilizarem a metodologia da resolução de problemas nas aulas de matemática em um ambiente de formação na perspectiva de trabalho colaborativo. O objetivo deste texto é apresentar como os participantes foram modificando o olhar que tinham para a resolução de problemas e como incorporaram a resolução de problemas como estratégia metodológica para ensinar matemática nos anos iniciais. Dezesseis professores dos anos iniciais participaram da Atividade Curricular de Integração Ensino, Pesquisa e Extensão (ACIEPE): "A matemática nos anos iniciais: programa de formação contínua de professores dos anos iniciais da Secretaria Municipal de Educação de São Carlos", durante o primeiro semestre de 2011, para estudar, discutir e refletir sobre suas práticas ao trabalhar com a metodologia da resolução de problemas em aulas de matemática dos anos iniciais. Os dados empíricos foram construídos através de questionário, entrevistas semiestruturadas, registro em áudio e vídeo, material escrito, diário de campo reflexivo produzido pelos professores participantes e pela pesquisadora, que atuou como formadora e acompanhou ações dos professores nas aulas de matemática em suas escolas. A análise dos dados indica que a abordagem do tipo trabalho colaborativo contribuiu para que os professores participantes ressignificassem saberes e concepções sobre resolução de problemas nas aulas de matemática e implementassem práticas mais significativas em suas aulas.
\end{abstract}

Palavras-chave: Prática docente. Resolução de problemas. Formação matemática. Desenvolvimento profissional. Trabalho colaborativo.

\begin{abstract}
This article is part of a research of a descriptive and interpretative nature that investigated the challenges, dilemmas, knowledge and learning that emerge in the process of continuous teacher education of teachers of the early years when studying and using the methodology of problem solving in mathematics classes in a teacher education environment in the perspective of collaborative work. The purpose of this words is to present how the participants modified their gaze for problem solving and how they incorporated problem solving as a methodological strategy for teaching mathematics in the early years. Sixteen teachers from the initial years participated in the Curriculum Activity of Teaching, Research and Extension (ACIEPE): "Mathematics in the initial years: a continuous education teacher program for teachers of the initial years of the Municipal Secretary of Education of São Carlos", during the first semester of 2011, to study, discuss and reflect their practices to work with a methodology of problem solving in math classes of the early years. The empirical data were constructed through a questionnaire, semi-structured interviews, audio and video records, written material, reflective field diary produced by the participating teachers and the researcher, who acted as a teacher and monitored teachers actions in the math classes in their schools. The data analysis indicates that the collaborative work approach contributed to the participating teachers to re-characterize knowledge and problem solving concepts in math classes and to implement more meaningful practices in their classes.
\end{abstract}

Keywords: Teaching practice. Problem solving. Mathematical education. Professional development. Collaborative work.

Resumen: Este artículo hace parte de una pesquisa de naturaleza descriptiva y interpretativa, que investigó desafios, dilemas, saberes y aprendizájenes que emergen en el proceso de formación continua de profesores de los años 
iniciales al estudiaren y utilizaren la metodología de la resolución de problemas en las clases de matemáticas en un ambiente de formación en la perspectiva de trabajo colaborador. El objetivo de este texto es presentar cómo los participantes fueron cambiando la mirada que tenían para la resolución de problemas y cómo incorporaron la resolución de problemas como estratégias metodologicas para la enseñanza de matemáticas los años iniciales. Dieciséis profesores de los años iniciales participaron de Actividad Curricular de Integración Ensenãnza, Pesquisa y Extensión (ACIEPE): "Las matemáticas los años inciales: programa de formación continua de profesores de los años iniciales de la Secretaria Municipal de Educación de São Carlos", durante el primer semestre de 2011, para estudiar, discutir y reflexionar sobre sus prácticas al trabajar con la metodología de la resolución de problemas en clases de matemáticas de los años iniciales. Los datos empíricos fueron construídos a través de cuestionario, entrevistas semiestructuradas, registro en audio y vídeo, material escrito, diario de campo reflexivo producido por los profesores participantes y por la pesquisadora, que actuó como instructora y acompañó las acciones de los profesores en las clases de matemáticas en sus escuelas. El análisis de los datos indica que el abordaje del tipo de trabajo colaborador contribuyó para que los profesores participantes replanteasen saberes y concepciones sobre la resolución de problemas en las clases de matemáticas y implementasen prácticas más significativas en sus clases.

Palabras clave: Práctica docente. Resolución de problemas. Formación en matemáticas. Desarrollo profesional. Trabajo colaborador.

\section{INTRODUÇÃO}

A formação continuada, cenário da pesquisa de mestrado "Resolução de problemas na formação continuada e em aulas de matemática nos anos iniciais", foi construída e planejada a partir do interesse manifestado pela Secretaria Municipal de Educação de São Carlos, que buscou parceria com a Universidade Federal de São Carlos (UFSCar) para contribuir com a formação dos professores dos anos iniciais do ensino fundamental, principalmente em relação ao trabalho com o conhecimento matemático.

A pesquisa de mestrado1 foi desenvolvida no contexto de uma Atividade Curricular de Integração Ensino, Pesquisa e Extensão (ACIEPE): "A matemática nos anos iniciais: programa de formação contínua de professores dos anos iniciais da Secretaria Municipal de Educação de São Carlos", que contou com o apoio financeiro da Pró-Reitoria de Extensão (PROEX) da UFSCar.

O grupo, constituído por 16 professores dos anos iniciais, voluntariamente, se inscreveu na ACIEPE e a organização da equipe/grupo que participou da formação continuada alicerçou a pesquisa que se deu numa perspectiva de trabalho colaborativo, considerando que programas de formação de professores, como preconiza Serrazina (2010), devem valorizar o desenvolvimento profissional do professor, uma formação matemática de qualidade para ele e o desenvolvimento curricular em matemática; reconhecer as práticas letivas como ponto de partida da formação; considerar as necessidades concretas dos professores relativamente às suas práticas curriculares em matemática; valorizar o trabalho colaborativo entre diferentes atores, dado que a dimensão coletiva do trabalho dos professores é extremamente importante; e valorizar as dinâmicas curriculares contínuas centradas na matemática. Esses programas precisam articular o conhecimento dos conteúdos a ensinar, o conhecimento didático e os recursos disponíveis para utilizar na sala de aula e nessa perspectiva.

O projeto de formação da ACIEPE foi pensado e construído num processo de trabalho coletivo, "na perspectiva da construção conjunta dos saberes e aprendizagens, para o desenvolvimento de práticas mais significativas de ensino e de aprendizagem da matemática" (OLIVEIRA; PASSOS, 2013, p. 874).

Havia a intenção de que tal projeto fosse desenvolvido nesta perspectiva e se constituísse em um grupo colaborativo (OLIVEIRA, 2012).

O caminhar do grupo seguiu um direcionamento - imbuído de significados e sentidos que evidenciam a importância da formação continuada - e uma dinâmica de trabalho coletivo e colaborativo, para compartilhar os desafios, os dilemas, os saberes e as aprendizagens da prática; e focou a metodologia da resolução de problemas nas aulas de matemática.

Segundo Oliveira (2012, p. 27), "cada encontro da formação foi pensado, planejado e discutido a partir das temáticas apresentadas pelos participantes, numa construção coletiva do conhecimento e num processo colaborativo de formação continuada". Nesse contexto, o valor de cada encontro, as idas ao local da formação, os encontros no grupo, marcaram "o lugar e o tempo de chegada

\footnotetext{
1 OLIVEIRA, Sandra Alves de. Resolução de problemas em aulas de matemática nos anos iniciais: desafios, dilemas, saberes e aprendizagens da prática docente. 2012. 185f. Dissertação (Mestrado em Educação) - Universidade Federal de São Carlos, PPGE/UFSCar, 2012.
} 
do grupo, uma parada no caminhar para colher as produções, as conquistas, o aprendido. [...] pela abertura às adequações necessárias e ao acolhimento das diferenças" (PLACCO; SOUZA, 2006, p. 48). Dessa forma, não foi a formadora-pesquisadora que estabeleceu quais conteúdos de matemática e quais estratégias seriam apresentadas e discutidas na formação, mas a pretensão, 0 objetivo ou a necessidade de cada participante, expressos na ficha de identificação preenchida no primeiro encontro que definiram esses aspectos.

No percurso formativo, a formadora-pesquisadora procurou conquistar a confiança do grupo, levando em conta os saberes e as experiências dos professores e compartilhando com eles seu conhecimento matemático; sua compreensão da matemática; suas experiências e saberes da prática profissional; e sua disponibilidade em compartilhar significados e sentidos no espaço de formação (PLACCO; SOUZA, 2006).

Por meio das discussões no grupo, compartilhando os saberes e as experiências da ação pedagógica, aprendemos a olhar de outra forma o que fazemos, buscando ação e reflexão compartilhadas, como também novas aprendizagens sobre o trabalho docente e a ressignificação de nossos saberes e práticas.

Com o objetivo de apresentar como os participantes desse processo formativo, com perspectivas de trabalho colaborativo, foram modificando o olhar que tinham para a resolução de problemas e como incorporaram a resolução de problemas como estratégia metodológica para ensinar matemática nos anos iniciais, este artigo está organizado em três seções: na primeira apresentam-se considerações teóricas referentes à formação e à atuação de professores articuladas com o movimento vivido por eles; na segunda, apresentam-se o contexto da pesquisa, os objetivos e os instrumentos metodológicos; na terceira discutimos elementos que revelam novos olhares para a resolução de problemas e como os professores participantes incorporam essa perspectiva no processo de ensinar matemática Por fim, tecemos algumas considerações finais, refletindo a respeito da importância de formações continuada de professores na perspectiva de grupo colaborativo para o desenvolvimento profissional de todos que dele participam.

\title{
2 A IMPORTÂNCIA DE UM AMBIENTE DE FORMAÇÃO E ATUAÇÃO DOCENTE, NA DIMENSÃO DO TRABALHO COLETIVO-COLABORATIVO PARA O DESENVOLVIMENTO PROFISSIONAL DE UM GRUPO DE PROFESSORES DOS ANOS INICIAIS
}

Sendo o desenvolvimento profissional um processo que se prolonga ao longo da carreira, Ferreira (2003, p. 42) destaca

\begin{abstract}
a importância de um ambiente de formação e atuação docente, na dimensão do trabalho coletivo-colaborativo, para proporcionar aos professores oportunidades de desenvolver-se profissionalmente, de virem a ser sujeitos da sua própria formação, no compartilhamento de suas experiências, saberes e aprendizagens da prática docente e também na busca de inovações e de soluções para os problemas que emergem do cotidiano escolar.
\end{abstract}

Ao considerar tais fatores como importantes para a formação profissional docente, é preciso acrescentar a essa ponderação de Ferreira (2003) a afirmação de Ponte (1994, p.175): "o desenvolvimento profissional dos professores, dentro e fora da escola, é o resultado da sua reflexão e participação em oportunidades de formação que melhorem e ampliem o seu desenvolvimento e progresso".

Em consonância com as considerações desses pesquisadores, Mizukami (2006, p. 214) salienta que

os processos de aprender a ensinar, de aprender a ser professor e de desenvolvimento profissional de professores são lentos, iniciam-se antes do espaço formativo dos cursos de licenciatura e se prolongam por toda a vida. A escola e outros espaços de conhecimento são contextos importantes nessa formação. Conhecimentos teóricos diversos assim como aqueles que têm como fonte experiência pessoal e profissional são objetos de aprendizagens constantes. 
A formação de professores deverá ser organizada como mais um espaço em que o processo de ensino-aprendizagem possibilite o diálogo, a troca e a produção de saberes.

Como forma de organização do trabalho docente, os grupos de estudos têm o propósito de contribuir para o desenvolvimento profissional. Indubitavelmente, é o início para o processo de mudança na formação do professor que ensina matemática nos anos iniciais. Eles constituem uma alternativa e um espaço para apoiar o processo de desenvolvimento profissional e de mudança dos profissionais envolvidos numa formação continuada, sendo possível a sua constituição. A participação no grupo contribui para a compreensão de vários aspectos relacionados ao ensino de matemática (GIMENES; PENTEADO, 2008).

Fiorentini (1995, p. 30) quando defende o trabalho em grupos preconiza que, no processo de discussões em grupos, os professores podem ressignificar os conhecimentos que adquiriram ao longo da formação.

Quando o professor participa de um grupo de estudos, ele é levado a uma análise mais sistemática de suas práticas, o que Ihe possibilita identificar problemas e perceber a necessidade de mudança, que, segundo Ferreira (2003), depende do desejo e das condições favoráveis: apoio, suporte intelectual, espaço e tempo, que fazem do grupo de estudos um ambiente propício para tais condições.

Este processo pode ser estimulado, de acordo com Serrazina (1999, p. 24), "pela presença de alguém que os ajude a refletir sobre suas próprias práticas e de um ambiente onde possam discutir e partilhar significados, de forma a adquirirem mais conhecimento matemático e maior confiança nas suas próprias capacidades para aprender mais matemática".

Embora reconheçamos que a constituição de um grupo de formação de professores ou de um grupo de estudos não seja uma tarefa simples, acreditamos que, se houver uma programação prévia, voltada para a construção de um ambiente que promova reflexões sobre a ação pedagógica e o interesse dos envolvidos, o resultado poderá ser satisfatório. A formação de grupos de estudo, segundo Passos e Andrade (2010, p. 26),

é um dos meios pelos quais o professor consegue desenvolver-se. Os grupos de estudos têm se mostrado como uma instância significativa na qual o professor pode aprender e ensinar, expor suas inquietações e buscar caminhos para resolver seus problemas da prática. Há evidências de que, muitas vezes, o desenvolvimento do professor pode ocorrer pelo empenho e apoio que o grupo lhe oferece.

Para a constituição de um grupo, a confiança pauta-se na lealdade, no diálogo e na reciprocidade como ingredientes básicos nos momentos de tomada de decisão. Assim, "o estabelecimento da confiança é essencial para a criação de relações de trabalho em colaboração que sejam eficazes e significativas" (HARGREVES, 1998, p. 284, apud NACARATO, 2005, p. 184).

Para que se constitua um ambiente de trabalho coletivo e colaborativo, é essencial esse processo de cooperação investigativa, tanto na interação estudante-estudante quanto na interação estudante-professor.

Para quem se propõe a participar de uma atividade cooperativa, Alro e Skovsmose (2006, p. 105) salientam a importância de "estabelecer contato como forma de criar uma sintonia com o colega e com as perspectivas dele". Assim, o contato irá possibilitar "estar presente e prestar atenção ao outro e às suas contribuições, numa relação de respeito mútuo, responsabilidade e confiança" (ALRO; SKOVSMOSE, 2006, p. 106). Esses autores ainda destacam que "o processo de estabelecer contato tanto como uma preparação para a investigação quanto como uma atitude positiva de relacionamento entre os participantes durante a cooperação os torna abertos à investigação".

Ferreira (2006, p. 152) enfatiza a relevância da participação docente no grupo colaborativo como fonte de aprendizagem, uma vez que ali são criadas as "oportunidades para o professor explorar e questionar seus próprios saberes e práticas, bem como para conhecer saberes e práticas de outros professores, permitindo-lhes aprender por meio do desafio das próprias convicções". Trabalhando de forma colaborativa, os participantes do grupo reúnem-se e buscam, juntos, empenharse na realização do objetivo comum, tendo, portanto, mais energia e determinação nas ações. É importante destacar ainda que várias pessoas trabalhando juntas e com experiências, competências e perspectivas diversificadas, podem reunir mais recursos de diferentes naturezas e concretizar, com 
êxito, um dado trabalho. Há, desse modo, um acréscimo de segurança para promover mudanças e iniciar inovações. Em conjunto, no grupo, os participantes interagem, dialogam e refletem, criando possibilidades de aprendizagem mútua e melhores condições para enfrentar, com êxito, as incertezas e os obstáculos que surgem no percurso da formação (BOAVIDA; PONTE, 2002).

A parceria professor e pesquisador, escola e universidade tem muito a contribuir para o desenvolvimento de práticas mais significativas e consistentes de ensino-aprendizagem da matemática e para o "processo de desenvolvimento profissional, numa prática pautada num trabalho colaborativo em que os docentes se sentem à vontade para relatar seus sucessos e fracassos" (NACARATO, 2005, p. 192).

\section{METODOLOGIA DA INVESTIGAÇÃO: caminhos trilhados}

Para atingir o objetivo proposto foi desenvolvida uma pesquisa de cunho qualitativo que teve como foco 16 professores que participaram de um processo formativo, suas reflexões e suas práticas focalizando a resolução de problemas. Entende-se que, nesse caso, no contato direto do pesquisador com a situação estudada, a obtenção de dados descritos enfatiza mais o processo do que o produto tendo a preocupação de retratar a perspectiva dos participantes (LÜDKE; ANDRÉ, 1986). Foi justamente essa a preocupação deste estudo, perceber a mudança de olhar dos professores para a resolução de problemas nas aulas de matemática dos anos iniciais. A ênfase foi no processo vivido pelos professores, retratando suas perspectivas, aprendizagens e ressignificações sobre o tema estudado. O ambiente da formação continuada e de salas de aula dos 16 professores participantes da ACIEPE caracterizou o ambiente natural desta pesquisa.

Desse grupo formado por 15 professoras e um professor, sendo que 15 eram licenciados em Pedagogia e uma professora, no momento da pesquisa cursava Pedagogia na modalidade de EaD. Dos 16, 12 também tinham formação no Magistério (Ensino Médio). O tempo de magistério era variado: três professoras estavam em início de carreira (com menos de 3 anos de experiência); 9 professores tinham de 4 a 15 anos de experiência no magistério e quatro professoras tinham mais de 20 anos de experiência no magistério.

Os 16 professores participantes da ACIEPE atuavam em seis diferentes escolas da rede municipal de São Carlos. Dessa forma, as trocas entre os professores e os trabalhos em grupos que foram propostos possibilitaram um maior envolvimento e entrosamento entre colegas da própria escola e de outras escolas.

No desenvolvimento da pesquisa, a formadora-pesquisadora procurou participar, compreender e interpretar os dados coligidos nas interações interpessoais e na coparticipação (CHIZZOTTI, 1995) dos professores que participaram dos 16 encontros formativos, no primeiro semestre de 2011, sempre às quintas-feiras, das $19 \mathrm{~h}$ às $21 \mathrm{~h}$. A discussão seja a respeito das situações e das tarefas sobre a resolução de problemas durante a formação, ou das aulas que foram acompanhadas nas visitas e nas parceiras estabelecidas nas escolas foram na perspectiva da constituição de trabalho colaborativo..

O trabalho de campo com esses professores pode ser considerado na perspectiva da pesquisa participante, em um processo colaborativo de formação continuada. O contato pessoal do pesquisador com o foco da pesquisa (LÜDKE; ANDRÉ, 1986) foi possibilitado, nesta pesquisa, no espaço da formação continuada e nas salas de aula observadas na perspectiva de um trabalho colaborativo e de aprendizagem colaborativa.

Encontramos em Ibiapina (2008, p.75) fundamentos para entender a ressignificação que os professores apresentam a respeito da resolução de problemas a partir da ação formativa, no qual "é preciso estimular o professor a responder as perguntas: Como posso agir diferentemente? [...] $\mathrm{O}$ que poderia fazer de forma diferente? O que considero pedagogicamente importante? O que tenho de fazer para mudar minha prática?". Os professores participantes da pesquisa foram estimulados a pensar e responder perguntas como essas.

Os dados constituídos para a análise foram coletados por meio de gravação em áudio e vídeo, de entrevistas semiestruturadas; material produzido pelos professores para aplicação da metodologia da resolução de problemas em suas aulas; diário de campo reflexivo produzido pelos professores a partir do vivido nos encontros; diário de campo reflexivo da pesquisadora.

É importante destacar que a construção dos dados foi se estabelecendo uma relação de parceria entre os professores participantes e formadora-pesquisadora que ocorriam nos momentos 
de estudo, na preparação e reflexão sobre a metodologia da resolução de problemas e nas atividades de ensino desenvolvidas por eles em sala de aula dos anos iniciais.

O material escrito produzido pela pesquisadora refere-se a registros reflexivos feitos a partir das conversas realizadas com os professores nos encontros, nas escolas, nos encontros individuais de preparação das atividades de resolução de problemas e também em conversas informais surgidas no decorrer do semestre.

Como sugerido por Bardin (2011), a análise iniciou-se por uma leitura flutuante dos dados, isto é, na primeira aproximação com a totalidade dos dados coletados, buscamos familiarizar-nos com o conteúdo das informações contidas nas fontes. Posteriormente, selecionamos, dentre os documentos, os revelaram mudanças no olhar que os professores tinham para a resolução de problemas nas aulas de matemática.

Para este texto trazemos duas dimensões de análise: na primeira apresentamos reflexões sobre a visão de resolução de problemas nas aulas de matemática explicitadas pelos professores participantes e percebidas pela formadora-pesquisadora a partir de discussões no grupo de estudos, nas práticas pedagógicas de professoras, nas respostas dadas ao questionário e nas entrevistas realizadas; na segunda apresentamos elementos que permitiram identificar como essa visão foi se transformando, revelando aprendizagens e ressignificações que possibilitam aos professores modificações em sua prática.

\section{A VISÃO SOBRE RESOLUÇÃo DE PROBLEMAS SE TRANSFORMANDO NA AÇÃO FORMATIVA}

Constatamos a necessidade de refletir sobre os desafios e os dilemas encontrados pelos professores dos anos iniciais, ao trabalhar com a resolução de problemas nas aulas de matemática no início das ações formativas, por outro lado, a literatura apontava que quando professores compartilham os saberes de sua ação pedagógica no processo de ensino e aprendizagem da matemática, pesquisam e buscam novas fontes teóricas e novas alternativas de ação em sala de aula, é possível romper com a prática tradicional do ensino.

Através de um questionário, que procurou contemplar questões sobre a resolução de problemas, buscamos conhecer o que o grupo de 16 professores pensava acerca dessa temática e como a resolução de problemas vinha fazendo parte das suas aulas de matemática. Outras questões enfocando a resolução de problemas buscaram compreender/identificar experiências anteriores, saberes e aprendizagens que eles tiveram ao longo de sua prática pedagógica.

Durante a formação eram apresentadas algumas das visões expressas por eles de modo a fomentar a discussão. A professora Manuela na resposta ao questionário, via o problema como um obstáculo para a aprendizagem dos alunos e para o ensino de matemática.

Em se falando de aprendizagem o problema para mim é um obstáculo, pois sempre foi difícil a solução dos mesmos. (Professora Manuela, questionário, mar. 2011).

Na minha época tinha um livro chamado Nossa vendinha. Lembra disso? Era um negócio tipo assim: nossa vendinha tinha terreno para vender. Eu ficava com aquilo na cabeça e não me conformava. Como é que uma venda tem terreno. Ela tem casa. A parede e a casa tinham não sei quantos metros. Aquilo não entrava e eu não conseguia aprender, eu não conseguia assimilar isso. Enquanto eu estava acostumada com venda, eu ia na venda e comprava o quê? Comprava arroz, feijão e ia buscar as coisas da casa nas minhas mãos, nunca ia lá comprar um terreno, uma casa. Então, não cabia na minha cabeça. Eu tinha muita dificuldade para entender porque eu tinha que calcular a área de um terreno e de uma casa que o cara estava vendendo na nossa vendinha. E era assim: Ensinou as quatro operações. A tabuada era obrigatória. Se não soubesse a tabuada não ia conseguir resolver nada. $E$ aí você tinha que saber a tabuada e as quatro operações. Depois eles colocavam na nossa vendinha. Tinha na nossa vendinha que ler, entender e fazer. Era horrível, era um massacre. Então eu passei o resto da minha vida tentando entender e pelo menos gostar um pouquinho da matemática. $E$ foi na faculdade que eu consegui que um professor sentasse comigo e mostrasse assim: olha, número é um negócio lindo e você vai gostar.

Tanto que a primeira prova que entreguei na faculdade para esse professor eu tirei 10 e foi um negócio muito emocionante. Eu nunca na minha vida tinha conseguido. De repente eu comecei a entender. O professor Joãozinho foi para mim o melhor na matemática. Ele mostrou 
a importância da matemática e como lidar. Foi um trauma para mim o primário, na época era o ginásio. Dificuldade por conta da nossa vendinha.

Como professora, consigo planejar a aula de matemática para os meus alunos, trabalhar os conteúdos de matemática e fazer com que os meus alunos entendam, por exemplo, os números decimais, por que tem dezena, centena e outros. Hoje consigo fazer isso porque o professor Joãozinho me ajudou a entender a matemática. (Professora Manuela, depoimento, maio 2011).

O problema é entendido por esta professora como um obstáculo para a aprendizagem e para o ensino de matemática e é exemplificado por ela como sendo sempre algo difícil para ser resolvido. Como ela relatou as dificuldades relacionam-se a compreensão dos conteúdos matemáticos e com o contexto do livro Nossa vendinha. Nessa situação apresentada, percebemos que Manuela não conseguiu ver a relação entre a venda de um terreno na "nossa vendinha", pois suas vivências, nas idas à venda ao mercado eram para comprar arroz, feijão e não um terreno. É claro que não devemos, como apontam Passos e Romanatto (2010, p. 27),

ensinar apenas aqueles conhecimentos necessários ao dia a dia do estudante, pois isso seria impedi-lo de ter acesso a outros conhecimentos. Porém, é preciso partir da realidade do educando, daquilo que tem significado para ele, para então chegar à teoria e depois retornamos à prática para, então compreendê-la a partir de novos conhecimentos.

Contudo, no caso resgatado da memória da professora Manuela o contexto apresentado atrapalhou o entendimento dos conteúdos matemáticos pretendidos, assim "os problemas" não eram trabalhados para ensinar matemática, mas para ver o que o aluno sabia de matemática. $A$ professora Manuela ressalta que na universidade superou esse obstáculo, conseguiu entender melhor a importância dos números nos cálculos realizados, bem como planejar as suas aulas de matemática para trabalhar os conteúdos matemáticos com seus alunos.

De acordo com Saviani (1985), problema é uma questão cuja resposta desconhecemos e necessitamos conhecer. A narrativa da professora Manuela referente ao "problema da vendinha" que lhe causou estranhamento na educação básica não atende ao que o autor referido sugere. Não havia naquele momento vivido pela professora a necessidade de resolver um problema, embora 0 desconhecimento da resposta do problema e a vontade de encontrá-la, tenha acompanhado seu processo de formar-se professora.

A professora Roseli exemplifica como vê o problema, ou seja, para verificar se os alunos entenderam um conteúdo explicado. Ela fazia uso de problemas para que os estudantes aplicassem as regras e os algoritmos previamente trabalhados na explicação da professora.

Ao trabalhar o sistema monetário, por exemplo, ensino a parte inteira e a parte decimal e para verificar a aprendizagem, trago o problema. Tenho 9 notas de 5 reais. Peguei a minha compra no caixa no valor de 42 reais. Qual foi o meu troco? Quais as notas e moedas que poderei receber? (Professora Roseli, questionário, mar. 2011).

Observa-se através desses depoimentos que essas professoras trabalhavam a resolução de problemas em momento posterior ao da explicação do conteúdo. Os estudantes utilizavam os procedimentos algorítmicos para chegar à solução do problema. Os professores ressaltam também que trabalhavam com os problemas convencionais trazidos no material didático utilizado.

Durante a formação essa situação foi problematizada tendo como referência o que assevera Serrazina (2010, p. 10), "o professor precisa de 'desempacotar' a matemática, isto é, não pode limitar-se às definições e conceitos matemáticos 'acabados', mas tem de ensinar de modo que os alunos vão 'construindo' esses conceitos com compreensão”. Discutiu-se, por exemplo, que o trabalho com o sistema monetário, poderia partir das situações-problemas vivenciadas no cotidiano das crianças e da discussão sobre a importância do sistema monetário para a vida das pessoas e da economia do país. Quando os conceitos e as definições são apresentados e discutidos de forma contextualizada significativamente e problematizadora, é possível para os alunos construí-los com compreensão. 
No decorrer do processo de resolução dos problemas as informações poderão ser compartilhadas entre o professor e os estudantes, deixando que a atividade continue sendo desafiadora para os estudantes. Hiebert et al. (1997, p. 36), citados por Van de Walle (2009, p. 75), destacam que "a informação pode e deve ser compartilhada sem resolver o problema [e], não eliminando a necessidade dos alunos refletir sobre a situação e desenvolver métodos de resolução que eles compreendam".

As atividades desafiadoras ou os problemas devem ser propostos nas aulas de matemática, para possibilitar uma perspectiva compartilhada e o pensar matematicamente, promovendo, assim, momentos de problematizações entre os participantes nas situações apresentadas na resolução do problema. Mengali (2011, p. 53) destaca que "selecionar e propor aos alunos tarefas problematizadoras pode ser o início de um caminho que conduza a essa nova cultura de aula de matemática". Dessa forma, é preciso que os problemas sejam bem escolhidos, de modo tal que conduzam os alunos ao pensamento matemático, como proposto por Schoenfeld (1996).

Portanto, ao propor os problemas matemáticos nas aulas, deve-se levar em consideração que estes têm como objetivos: "desenvolver estratégias e processos gerais ou específicos do pensamento matemático, ou motivar e tornar significativa a introdução de uma noção" (VILA; CALLEJO, 2006, p. 164).

Discutiu-se durante a formação resultados de pesquisas como a realizada por Mengali (2011) que aponta para as potencialidades de um ambiente de trabalho coletivo e colaborativo com resolução de problemas, estabelecido numa relação dialógica, de interações e de intervenções da professora.

Discutir esses aspectos sobre a resolução de problemas no grupo durante o processo formativo foi na perspectiva do que Nacarato $(2005$, p. 188) pensa a respeito do "trabalho coletivo, na escola, possibilita que esta passe a ser considerada uma comunidade de aprendizagem". Assim se expressa Hargreaves a esse respeito:

A colaboração aumenta as oportunidades dos professores aprenderem uns com os outros ao nível da sala de aula, dos departamentos e das escolas. Tal colaboração é uma fonte poderosa de aprendizagem profissional e de melhoramento no desempenho das tarefas [...] A colaboração encoraja os professores a encarar a mudança, não como uma tarefa a realizar, mas como um processo infinito de aperfeiçoamento contínuo [...]. (HARGREAVES, 1998, p. 279 apud NACARATO, 2005, p. 188).

Concordamos com Domite (2009) quando ela ressalta que ainda encontramos, nas aulas de matemática, muito mais explicações dos conteúdos do que perguntas, o que não traz contribuições para o pensar matematicamente. Isso é preocupante, pois, quando o professor explica o problema e diz quais estratégias a serem utilizadas ele aponta o que e como fazer, os estudantes, apenas ouvindo o professor expor seu pensamento, não desenvolverão autoconfiança nem habilidades para utilizar suas estratégias no processo de resolução dos problemas.

O fragmento do diário reflexivo elaborado pela professora Paula descreve e reflete acerca da metodologia da resolução de problemas decorrente do processo formativo que participou. Salienta sua oportunidade de conhecer, na formação, os diferentes tipos de problemas e a possibilidade de sua utilização nas suas aulas.

Durante a ACIEPE pudemos conhecer diferentes tipos de problemas: problemas convencionais e não convencionais; problemas sem solução e outros com mais de uma solução; problemas com excesso de dados; problemas de lógica; problemas a partir de operação ou a partir da resposta. Em grupos realizamos atividades para discutir sobre os diversos tipos de problemas e resolvê-los. Nesta oportunidade, fomos instigados a refletir sobre a possibilidade e importância de inserir em nossas aulas atividades que envolvam a metodologia da resolução de problemas, pensando que tal metodologia auxilia os alunos a considerarem todo o processo de resolução: desde a leitura e interpretação dos dados; as estratégias que utilizará para encontrar uma solução e o aprendizado que será significativo, isto porque, neste caso, a resolução ultrapassou a memorização de regras e fórmulas. (Fragmento do diário reflexivo da professora Paula - jun. 2011). 
O excerto nos remete ao que Placco e Souza (2006) pensam sobre o processo de significação das experiências, da produção de saberes e das aprendizagens da prática docente e do processo de formação, ou seja, da necessidade do formador desempenhar o papel de mediador nas relações de ensino-aprendizagem, considerando os saberes do grupo de professores e oferecendo pistas para que novas atribuições de significado possam ser realizadas por eles.

Segundo Mizukami et al. (2002, p. 72), "para que os professores aprendam novas formas de ensinar precisam trabalhar com os pares - dentro e fora da escola -, de forma a aprender com os sucessos, os fracassos, os erros e as falhas e a partilhar ideias e conhecimentos".

Cochran-Smith e Llytle (1999) sugerem várias abordagens para o desenvolvimento profissional do professor, que incluem o conhecimento para a prática, o conhecimento em prática e o conhecimento da prática. $\mathrm{O}$ "conhecimento para a prática", como salientam essas autoras, envolve os conhecimentos que o professor precisa ter para o processo de ensino-aprendizagem: conhecimentos da matéria a ser ensinada, pedagógicos, de teorias de aprendizagem e de desenvolvimento humano; e estratégias avançadas e práticas eficientes de ensino de diversas disciplinas - o conhecimento sobre as bases disciplinares da educação, a organização de sala de aula, a avaliação, 0 contexto social e cultural da escola e o conhecimento da profissão de professor. As autoras ressaltam o "conhecimento em prática" como essencial ao ensino, uma vez que se encontra imbuído na prática ou nas reflexões que fazemos sobre ela. Dessa forma, pressupõe que os professores aprendam quando têm oportunidade de obter outros conhecimentos ou de aprofundar os seus próprios, por meio de atitude investigativa e reflexão sobre a sua experiência. Já o "conhecimento da prática", segundo essas autoras, refere-se ao "conhecimento que os professores precisam para ensinar bem e é gerado quando eles consideram suas próprias salas de aula locais para uma investigação intencional" (COCHRAN-SMITH; LLYTLE, 1999, p. 250). Assim, esse conhecimento diz respeito à articulação teoria-prática-teoria, em que o conhecimento e a teoria que são produzidos por outros poderão ser questionados e interpretados.

Segundo Cochran-Smith e Lytle (1999, p. 301-302), quando os professores trabalham juntos, "apresentam problemas, identificam discrepâncias entre teorias e práticas, desafiam rotinas comuns e se baseiam no conhecimento de outros para construir um enfoque gerativo"; e tentam, dessa forma, "tornar visível muito do que é considerado dado no ensino-aprendizagem".

Foi num trabalho coletivo e colaborativo que os conhecimentos teóricos e práticos sobre a metodologia da resolução de problemas foram compartilhados na ACIEPE e na sala de aula dos professores. Procurando aproximar o realizado com a concepção das autoras acima referidas, 0 "conhecimento para a prática" - para inserir na prática a metodologia da resolução de problemas, o professor precisa conhecer essa metodologia, para desenvolver situações de ensino-aprendizagem. O "conhecimento em prática" - ao utilizar essa metodologia na sua prática, o professor estará refletindo sobre suas ações na prática e aprofundando seus conhecimentos, a partir de outros conhecimentos, experiências, saberes e aprendizagens da prática. Já o "conhecimento da prática" para trazer e avaliar a metodologia da resolução de problemas no processo de ensinar matemática para os alunos.

Nessa perspectiva da dimensão do trabalho coletivo e colaborativo, o grupo de 16 professores dos anos iniciais refletiu acerca da sua própria experiência nas aulas de matemática e para obter aprofundamento teórico sobre a metodologia da resolução de problemas, utilizou o "conhecimento para a prática", o "conhecimento em prática" e o "conhecimento da prática".

As professoras Karina, que atua no $5^{\circ}$ ano e as professoras Fátima e Sônia que atuam no $3^{\circ}$ ano, de uma mesma escola planejaram uma aula para trabalhar o conteúdo Sistema Monetário Brasileiro a partir de um problema (Figura 1) que constava no material didático utilizado por elas. A pesquisadora participou da discussão desse planejamento que ocorreu na própria escola em que atuam, durante o período da Hora de Trabalho Pedagógico Compartilhado (HTPC). 
Figura 1 - Problema proposto

Márcia foi ao mercado e comprou $2 \mathrm{~kg}$ de arroz e $4 \mathrm{~kg}$ de feijão. Cada $\mathrm{kg}$ de arroz custa $\mathrm{R} \$ 2,00 \mathrm{e}$ cada $\mathrm{kg}$ de feijão custa $\mathrm{R} \$ 3,00$. Quanto Márcia gastou nesta compra?

Fonte: Dado da pesquisa

O problema foi lido, discutido e resolvido com cada turma a partir do seu contexto. Alguns questionamentos foram apresentados: O que era mais caro, o feijão ou o arroz? O valor do quilo de feijão daria para comprar um quilo de arroz? E, se Márcia tivesse comprado $6 \mathrm{~kg}$ de arroz, teria gastado o mesmo valor dos $4 \mathrm{~kg}$ de feijão?

O problema foi lido, discutido e resolvido com cada turma a partir do seu contexto. Alguns questionamentos foram apresentados: $O$ que era mais caro, o feijão ou o arroz? $O$ valor do quilo de feijão daria para comprar um quilo de arroz? E, se Márcia tivesse comprado $6 \mathrm{~kg}$ de arroz, teria gastado o mesmo valor dos $4 \mathrm{~kg}$ de feijão?

Os estudantes perceberam que esse problema poderia ser resolvido utilizando mais de uma operação, esquemas e desenhos. Segue na Figura 2 a transcrição das estratégias utilizadas pelos estudantes no processo da resolução do problema (Figura 1).

Figura 2 - Estratégias desenvolvidas na resolução do problema

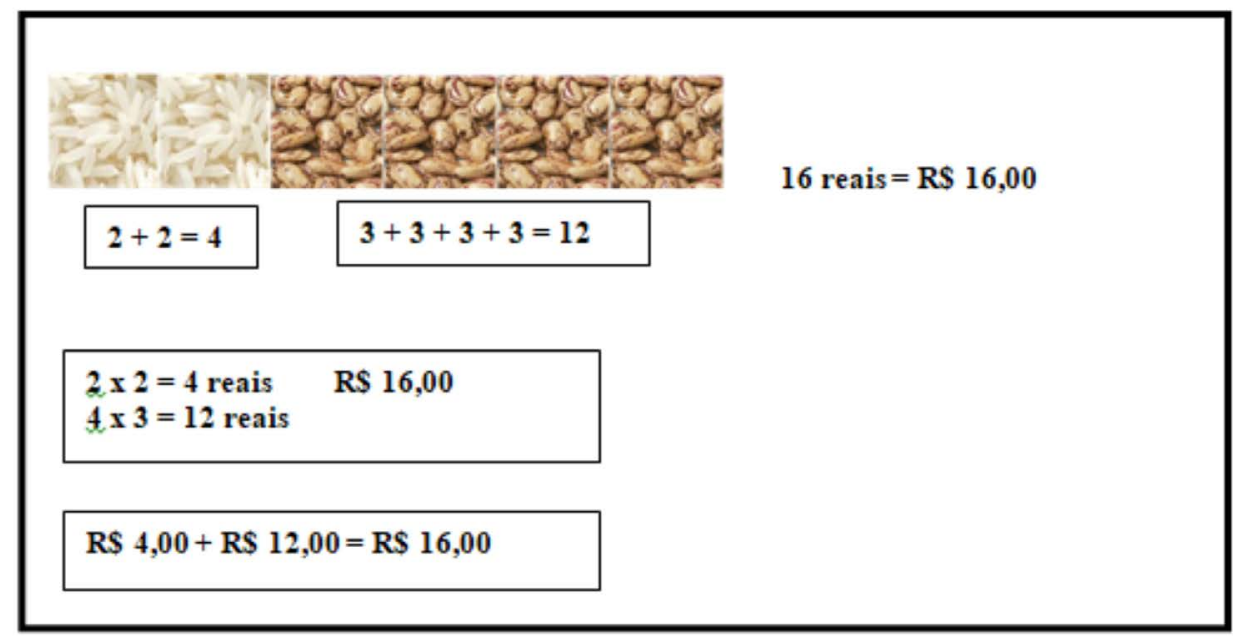

Fonte: Dados da pesquisa

Foi importante a percepção dos estudantes de que um mesmo problema pode ser resolvido de diversas maneiras e usando diferentes estratégias.

Após o momento de síntese desse processo pelas professoras, nas turmas em que trabalham, elas propuseram aos estudantes que criassem um problema a partir de um contexto apresentado por elas. A Figura 3 traz o enunciado da atividade:

Figura 3 - Criando um problema

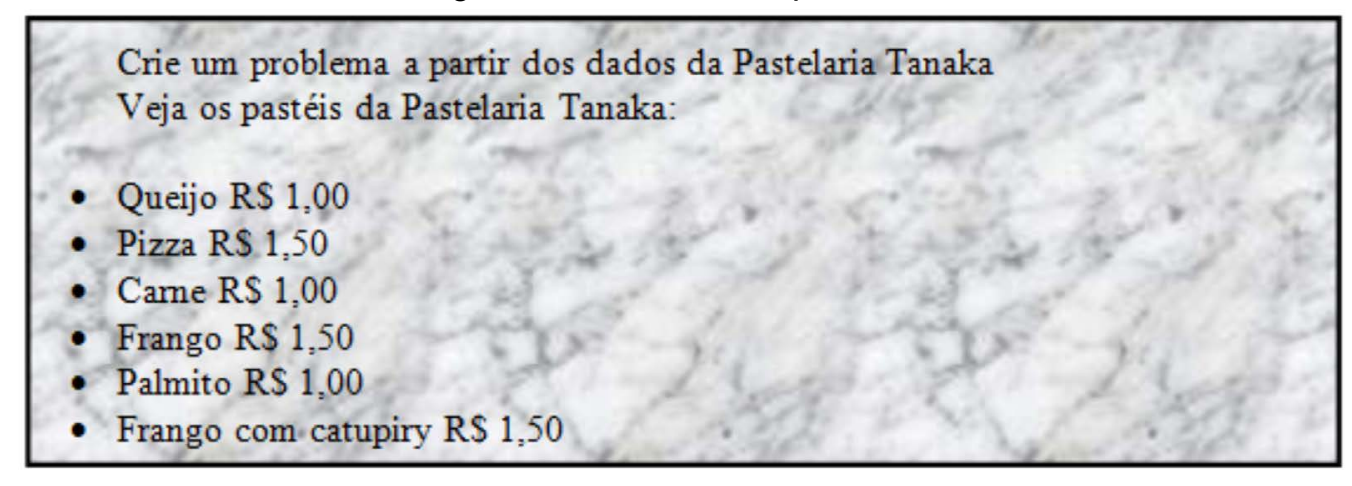

Fonte: Carvalho (2005, p. 50)

As professoras ressaltaram durante a entrevista e em seus depoimentos compartilhando com os demais participantes do grupo nos encontros da ACIEPE, que os estudantes conseguiram criar problemas com a proposta da Pastelaria Tanaka, embora as docentes, a princípio, imaginassem 
que eles não teriam essa condição, pois, nas suas práticas, raramente elas lhes faziam esse tipo de proposta.

$\mathrm{Na}$ Figura 4, apresentamos um problema que foi criado e resolvido - em dupla - pelos estudantes do $3^{\circ}$ e $5^{\circ}$ ano.

Figura 4 - Problemas criados pelos estudantes do $3^{\circ}$ e $5^{\circ}$ ano

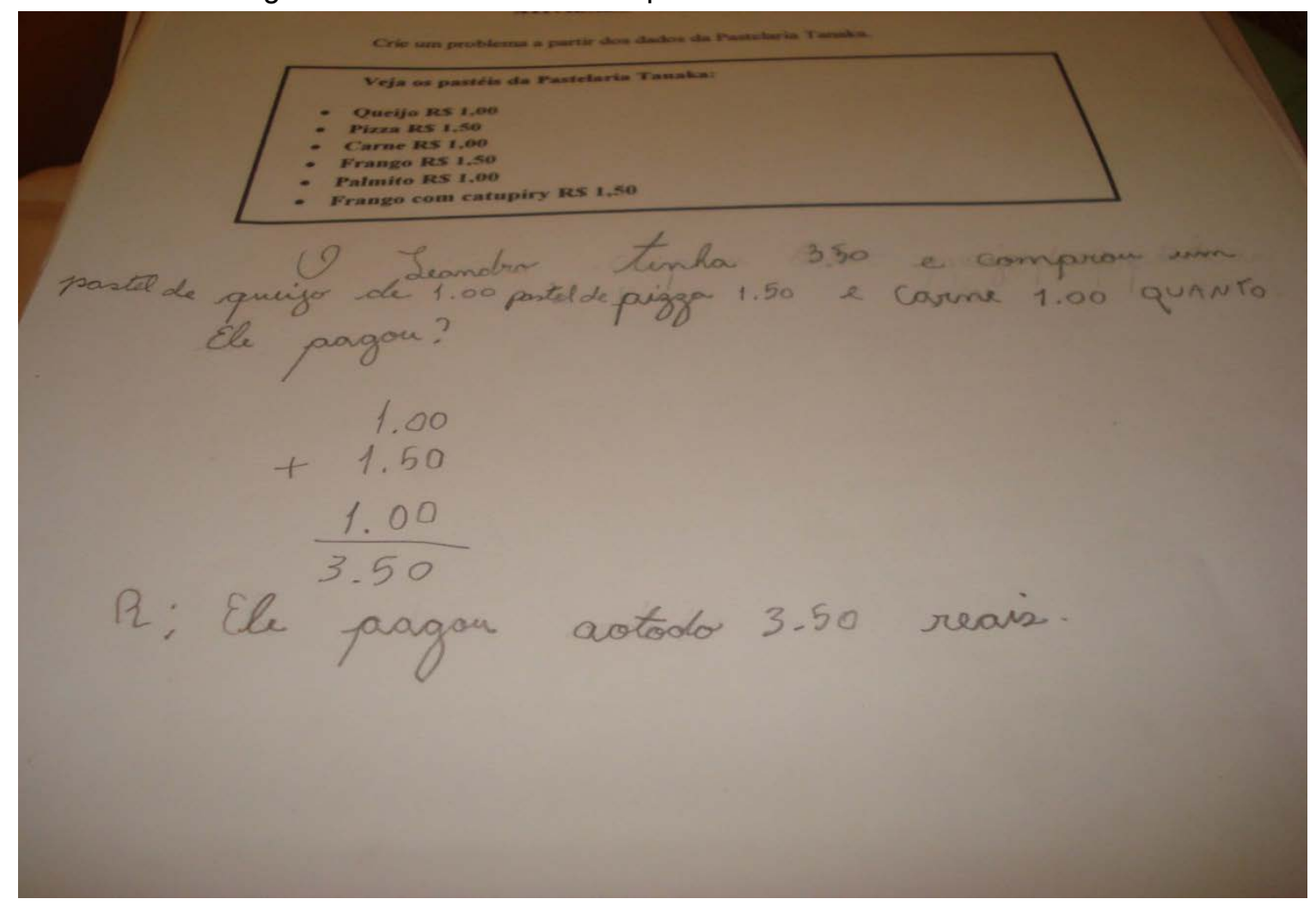

Fonte: Acervo da pesquisa

Foi possível observar, participando dessa aula, que alguns estudantes conseguiram, a partir dos problemas que foram propostos, criar novos problemas, enquanto outros tiveram dificuldades nessa elaboração. Observamos que a professora mediou as discussões na dupla de modo que concluíssem a tarefa. Houve uma boa participação das duplas nessa atividade, e, ao analisar os problemas criados, percebemos que eles usaram das suas ideias e não ficaram presos ao problema apresentado.

No desenvolvimento das aulas nas turmas do $3^{\circ}$ e $5^{\circ}$ ano foi utilizada a metodologia da resolução de problemas na perspectiva apresentada por Van de Walle (2009) e de Onuchic (1998, 1999) que propõem o ensino da matemática através da resolução de problemas. Os professores buscaram em suas práticas utilizar os conhecimentos teóricos e práticos vivenciados no processo de formação continuada.

É importante ressaltar que para o acompanhamento do planejamento e do desenvolvimento da dinâmica de trabalho com a metodologia de resolução nas turmas do $2^{\circ}, 3^{\circ}$ e $5^{\circ}$ ano, buscamos apoio em estudos teóricos referidos neste artigo e estudados no coletivo da formação. Procuramos, por exemplo, "articular o conhecimento dos conteúdos a ensinar, o conhecimento didáctico e os recursos disponíveis para utilizar na sala de aula" (SERRAZINA, 2010, p. 7).

A professora Ana enfatiza a relevância de trabalhar com a resolução de problemas e não somente com as contas isoladas. Por meio do problema, conteúdos matemáticos serão discutidos, conceitos matemáticos serão apropriados e novas compreensões da matemática, embutidas na situação-problema e nas problematizações criadas, serão formalizadas e construídas. Assim se expressou a professora Ana: "Desenvolve tudo. A continha solta é só a continha e o problema você vai ver se ele sabe armar, se ele sabe interpretar, quais as maneiras que ele está pensando". (Professora Ana, entrevista, set. 2011).

Ao perguntarmos aos professores participantes da formação se as atividades desenvolvidas na ACIEPE contribuíram de alguma maneira com sua prática em sala de aula, eles ressaltaram 
a contribuição teórica e prática da ACIEPE para o seu desenvolvimento profissional e para o desenvolvimento de outras propostas nas aulas de matemática.

No seu diário reflexivo, a professora Joana destaca que "o trabalho com situações-problema é muito importante e significativo para as crianças, pois, esses problemas propiciam o raciocínio da criança e beneficia a construção do conhecimento acerca da matemática". Na criação desse ambiente de resolução de problemas nas aulas de matemática, a leitura e a escrita se revelou fundamental na compreensão e na construção de sentidos e significados dos textos lidos e interpretados, dos problemas resolvidos. Isso foi observado no período da formação a importância da leitura e da escrita no contexto da resolução de problemas matemáticos nos momentos diversificados da organização do trabalho. Percebemos também as dificuldades encontradas pelos professores no momento em que liam o problema, principalmente o não convencional, e desenvolviam estratégias de resolução.

Na resolução do problema de lógica (STANCANELLI, 2001, p. 115), os professores puderam, individualmente e em grupo, e num segundo momento, discutir e resolver o problema proposto. No momento inicial da entrega do problema para os professores, nenhum teve resistência para resolvêlo. Todos puderam familiarizar-se com o problema, desenvolvendo uma estratégia de resolução. No momento de discutir e compartilhar suas ideias com os grupos formados, houve um recuo por parte da maioria dos professores, dizendo que a resposta encontrada por ele era a mesma do colega.

Figura 5 - Problema de lógica: Os irmãos
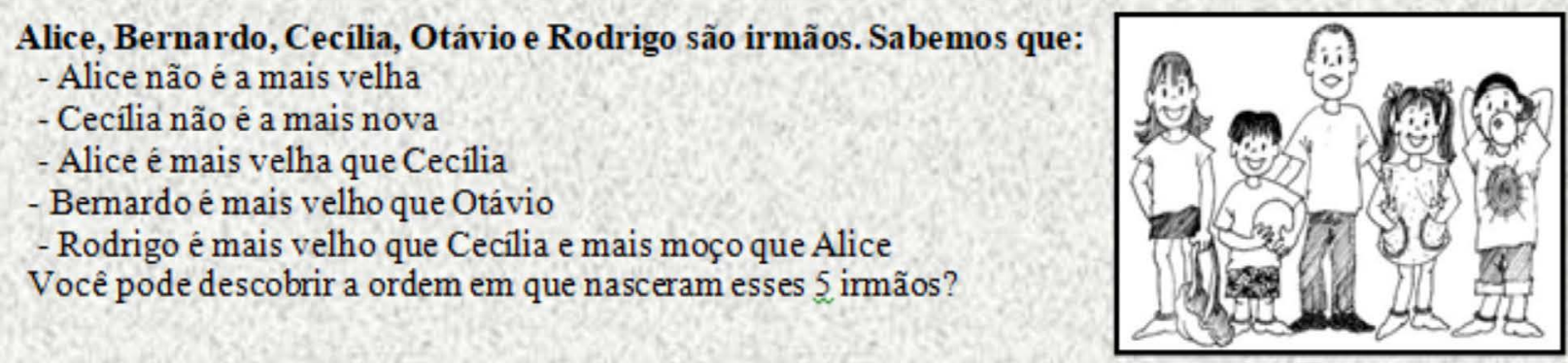

Fonte: Stancanelli (2001, p. 115)

A formadora-pesquisadora interveio no processo da resolução do problema, solicitando aos grupos formados para discutirem as estratégias desenvolvidas na resolução do problema proposto. Após sua intervenção, os professores compartilharam suas ideias.

$\mathrm{Na}$ apresentação da resolução do problema, cada grupo expôs a estratégia utilizada: $1^{\circ}$ grupo: resolveu o problema por eliminação dos nomes dos participantes no problema. $2^{\circ}$ grupo: resolveu o problema por eliminação dos nomes, mas focaram o olhar para a imagem. $3^{\circ}$ grupo: resolveu 0 problema por eliminação e, no final, descobriram que, como resposta, formaram a palavra BARCO. Resposta: Do mais velho ao mais novo: Bernardo, Alice, Rodrigo, Cecília e Otávio.

Analisando o que o grupo 3 descobriu no processo de resolução do problema, constatamos que, além de ler o problema e resolvê-lo, o grupo buscou fazer a leitura do resultado do problema, destacando, portanto, o significado da leitura e da escrita na resolução. Na solução apresentada, a formadora buscou discutir o problema com o grupo, sintetizando as ideias acerca do processo de resolução, dentro de uma determinada lógica de idades dos irmãos apontada pelos grupos nas diferentes estratégias que chegaram à mesma solução.

O problema de lógica, como destaca Stancanelli (2001), exigem raciocínio dedutivo. Para resolvê-lo o aluno deve se mostrar hábil em prever e checar situações, levantar hipóteses, buscar suposições, analisar e classificar dados. No processo de resolução desse tipo de problema, o aluno poderá utilizar do método de tentativa e erro, o uso de tabelas, diagramas e listas. Os grupos formados no encontro da ACIEPE, para resolução do problema (Figura 4) utilizaram do método de tentativa e erro e do uso de listas.

Durante a resolução de um problema é importante que o seu resolvedor se sinta desafiado e motivado a produzir seu conhecimento na solução do problema. Possibilitar, na proposta de resolução de problema, o estar junto com o colega, formando dupla ou grupo é uma boa oportunidade para que ocorra discussão de ideias com a participação de um ou mais colegas (VAN DE WALLE, 2009). 
Também é imprescindível nessa dinâmica de trabalho um ambiente de respeito às ideias do outro no processo de resolução do problema.

De acordo com Ball (1991), os professores dos primeiros anos necessitam de uma compreensão mais fundamentada da matemática que ensinam nas suas aulas. Nesse processo, é importante construir atividades e materiais, para a sala de aula, que proporcionem o aprender e o ensinar matemática numa relação dialógica que estabeleça a comunicação e a negociação de significados matemáticos com o professor e os alunos e entre eles.

Uma professora destacou no momento de compartilhar as ideias acerca do problema resolvido (Figura 4): "Tenho dificuldades em trabalhar com os estudantes os problemas não convencionais". Ao trabalhar com os problemas não convencionais, segundo Stancanelli (2001, p, 107), "os alunos têm contato com diferentes tipos de textos e desenvolvem sua capacidade de leitura e análise crítica, pois, para resolver a situação proposta, é necessário voltar muitas vezes ao texto a fim de lidar com os dados e analisá-los".

Constatamos nas falas das professoras, na entrevista realizada, que a participação deles na formação continuada sobre a resolução de problemas contribuiu para utilizar problemas não convencionais em suas aulas.

Usava mais os problemas convencionais, mas agora depois da ACIEPE estou mudando e uso os não convencionais. Estou buscando. Os problemas não convencionais levam os alunos a pensar mais sobre, ele tem que pensar mais e ajuda mais. Também estou propondo para os alunos criar problemas nas aulas de matemática. (Professora Karina, entrevista, set. 2011).

O problema não convencional dá mais resultado. Eles ficam interessados em saber. Esse problema é difícil, mas eles conseguem resolver. (Professora Roseli, entrevista, set. 2011).

Apresento os problemas não convencionais e proponho também para meus alunos criarem. Isso foi possivel por essa outra visão que foi dada sobre a resolução de problemas na ACIEPE. (Professora Sônia, entrevista, set. 2011).

No percurso da formação, pelas discussões dos conteúdos matemáticos e pelas atividades desenvolvidas, os professores participantes puderam parar para olhar, para escutar e refletir sobre a sua prática e formação matemática e compartilhar as suas experiências da trajetória estudantil e profissional.

De acordo com Ghedin e Franco (2008, p.71-72), "[...] o olhar quer ver sempre mais do que aquilo que lhe é dado ver. [...] Então, olhar é interpretar e perceber para poder compreender como são as coisas e os objetos investigados". Esse olhar reflexivo, interpretativo e investigativo perpassou todas as etapas do projeto de pesquisa e do desenvolvimento desta, como também todos os dados coletados por meio dos procedimentos metodológicos e dos instrumentos utilizados no percurso da pesquisa.

Constantemente, as reflexões sobre a metodologia da resolução de problemas nas aulas de matemática dos anos iniciais estiveram presentes, seja nos encontros formativos com o grupo de 16 professores, seja na observação participante nas instituições em que esses professores trabalham.

Ao utilizar, nas aulas de matemática dos anos iniciais do ensino fundamental, a metodologia da resolução de problemas percebemos que os professores mobilizam outros saberes a respeito do ensino da matemática, ou seja, revelou novo olhar para o uso da resolução de problemas para ensinar a disciplina de matemática.

\section{CONSIDERAÇÕES FINAIS}

A sala de aula têm se revelado um local de diferentes conflitos para os professores que ensinam matemática nos anos iniciais. A formação inicial, o currículo, as avaliações (internas ou externas), os processos de aprendizagem dos alunos, dentre outros aspectos, influenciam a rotina e ajudam a compor a complexidade de se ensinar matemática nos primeiros anos. A ideia de que formação docente - inicial ou contínua - se dá por um acúmulo de cursos, de leituras ou de informações vem sendo superada como apontam Oliveira e Passos (2008). Pois, os conhecimentos adquiridos só fazem sentido quando são incorporados ao fazer do professor, que testa em sua prática elementos que considera favoráveis para a aprendizagem dos alunos. 
No trabalho desenvolvido com os professores, foi possível vivenciar, na prática, a metodologia da resolução de problemas, possivelmente pelo modo com que o processo formativo se efetivou na ACIEPE, pois foi construído levando em consideração as experiências, os saberes, os desafios e os dilemas enfrentados pelos docentes no ambiente em que atuam.

Constatamos que professores, ao compartilharem suas experiências, revelavam uma visão de que a resolução de problemas ainda se encontra isolada do programa matemático. Como destacam Nacarato, Mengali e Passos (2009) são poucas as oportunidades de os professores dos anos iniciais de vivenciar projetos de formação que contribuam com o seu desenvolvimento profissional.

Como mencionado em Oliveira e Passos (2014, p. 85), "ao pensar sobre a resolução de problemas nas aulas de matemática, o grupo de professores teve a oportunidade de voltar-se para as situações teóricas e práticas dos saberes e das aprendizagens construídos ao longo da formação" e projetar práticas que superassem a visão reduzida que tinham.

Para Schroeder e Lester (1989, p. 34), "ao ensinar matemática através da resolução de problemas, os problemas são avaliados não somente como um propósito para aprender Matemática, mas, também, como um meio importante de fazer isso". Os autores ainda ressaltam que o ensino de matemática pela resolução de problemas não tem sido adotado, quer implícita, quer explicitamente, por muitos professores, autores de livros e promotores de currículos, mas constitui-se numa abordagem que merece ser considerada, desenvolvida e avaliada.

Percebemos através dos relatos dos professores, que é possível a utilização da metodologia da resolução de problemas nas aulas de matemática. Essa prática pode ajudar os estudantes a apropriarem-se dos conceitos matemáticos e de novas compreensões da matemática embutidas na situação-problema e na tarefa; e também favorece o desenvolvimento do seu raciocínio.

A partir do trabalho, realizado numa dimensão colaborativa, com discussões compartilhadas, nas vivências realizadas nos encontros formativos e nas salas de aulas dos professores, percebemos que a resolução de problemas é mais do que uma metodologia de ensino: é uma filosofia de ensino que está relacionada a ensinar e aprender mais do que o conteúdo de uma disciplina, ou seja, contribuiu para desenvolver outras capacidades (curiosidade, imaginação, criatividade, criticidade, autonomia, busca pelo conhecimento, entre outras) e também valores, tais como: autoestima, colaboração, respeito, entre outros, presentes nas várias situações-problema e problematizações apresentadas e criadas no contexto de cada aula, de cada escola, com estudantes e professores. 


\section{REFERÊNCIAS}

ALRO, H.; SKOVSMOSE, O. Diálogo e aprendizagem em educação matemática. Tradução de Orlando de A. Figueiredo. Belo Horizonte: Autêntica, 2006.

BALL, D. L. Reseach on teaching mathematics: making suject-matter knowledge part of the equation. In: BROPHY, J. (Ed.). Teachers' knowledge of subject matter as it relates to their teaching practice. Greenwich: JAI Press Inc., p. 1-48. 1991.

BARDIN, L. Análise de conteúdo. Tradução de Luís Antero Reto e Augusto Pinheiro. Lisboa: Edições 70, 2011. (Obra original publicada em 1977).

BOAVIDA, A M.; PONTE, J. P. Investigação colaborativa: potencialidades e problemas. In: GTI. (Org.). Reflectir e investigar sobre a prática profissional. Lisboa: APM, p. 43-55. 2002.

CARVALHO, M. Problemas? Mas que problemas?!: estratégias de resolução de problemas matemáticos em sala de aula. Petrópolis, RJ: Vozes, 2005.

CHIZZOTTI, A. Pesquisa em ciências humanas e sociais. 2. ed. São Paulo: Cortez, 1995.

COCHRAN-SMITH, M.; LLYTLE, S. L. Relações de conhecimento e prática: aprendizado de professores em comunidades. Tradução do GEPFPM/UNICAMP. Review of Research in Education, USA, $\mathrm{n}$. 24, p. 249-305, 1999.

DOMITE, M. do C. S. Formulação de problemas em educação matemática: a quem compete. Movimento - Revista da Faculdade de Educação da Universidade Federal Fluminense, EdUFF, Niterói, n. 14, p. 24-37, 2009.

FERREIRA, A. C. Metacognição e desenvolvimento profissional de professores de Matemática: uma experiência de trabalho colaborativo. 2003. 368 p. Tese (Doutorado em Educação: Educação Matemática) - FE/UNICAMP, Campinas, SP, 2003.

O trabalho colaborativo como ferramenta e contexto para o desenvolvimento profissional: compartilhando experiências. In: NACARATO, A. M.; PAIVA, M. A. V. (Org.). A formação do professor que ensina matemática: perspectivas e pesquisas. Belo Horizonte: Autêntica, p. 149-166. 2006.

FIORENTINI, D. Alguns modos de ver e conceber o ensino da matemática no Brasil. Zetetiké - Cempem - FE - Unicamp, Campinas (SP), v. 3, n.4, p.1-38, jan./dez. 1995.
GIMENES, J.; PENTEADO, M. G. Aprender Matemática em grupo de estudos: uma experiência com professoras de séries iniciais. Zetetiké - Cempem - FE - Unicamp, Campinas (SP), v. 16, n. 29, p. 7392, jan./jun. 2008.

GHEDIN, E.; FRANCO, M. A. S. A construção do olhar do pesquisador. In: Questões de método na construção da pesquisa em educação. São Paulo: Cortez, 2008. cap. 2.

HARGREAVES, A. Os professores em tempos de mudança: o trabalho e a cultura dos professores na idade pós-moderna. Portugal: MacGraw-Hill, 1998.

HIEBERT, J. et al. Making sense: Teaching and learning mathematics with understanding. Portsmouth, NH: Heinemann, 1997.

IBIAPINA, I. M. L. de Melo (Org.). Pesquisa colaborativa: investigação, formação e produção de conhecimentos. Brasília: Líber Livro, 2008.

LÜDKE, M.; ANDRÉ, M. E. D. A. Pesquisa em educação: abordagens qualitativas. São Paulo: EPU, 1986.

MENGALI, B. L. da S. A cultura da sala de aula numa perspectiva de resolução de problemas: o desafio de ensinar matemática numa sala multisseriada. 2011. 218 p. Dissertação (Mestrado em Educação) - Universidade São Francisco, USF, Itatiba (SP), 2011.

MIZUKAMI, M. das G. N. et al. Escola e aprendizagem da docência: processos de investigação e formação. São Carlos: EdUFSCar, 2002.

MIZUKAMI, M. das G. N. Aprendizagem da docência: conhecimento específico, contextos e práticas pedagógicas. In: NACARATO, A. M.; PAIVA, M. A. V. (Org.). A formação do professor que ensina matemática: perspectivas e pesquisas. Belo Horizonte: Autêntica, 2006. p. 213-231.

NACARATO, A. M. A escola como lócus de formação e de aprendizagem: possibilidades e riscos da colaboração. In: FIORENTINI, D.; NACARATO, A. M. (Org.). Cultura, formação e desenvolvimento profissional de professores que ensinam matemática: investigando e teorizando a partir da prática. São Paulo: Musa; Campinas, SP: GEPFPM-PRAPEMFE/UNICAMP, p. 175-195. 2005.

NACARATO, A. M.; MENGALI, B. L. da S.; PASSOS, C. L. B. A matemática nos anos iniciais do ensino fundamental: tecendo fios do ensinar e do aprender. Belo Horizonte: Autêntica, 2009. 
OLIVEIRA, S. A. de. Resolução de problemas em aulas de matemática nos anos iniciais: desafios, dilemas, saberes e aprendizagens da prática docente. 2012. 185f. Dissertação (Mestrado em Educação) - Universidade Federal de São Carlos, PPGE/ UFSCar, 2012.

OLIVEIRA, S. A. de; PASSOS, C. L. B. Resolução de problemas na formação continuada e em aulas de matemática nos anos iniciais: saberes e aprendizagens docentes. Educação Matemática Pesquisa, São Paulo, v. 15, número especial, p. 873-893, 2013.

Resolução de problemas e formação continuada de professores que ensinam matemática nos anos iniciais. In: NUNES, C. P.; FAGUNDES, H. P. P. (Org.). Formação de professores: questões contemporâneas. Curitiba/PR: CRV, p. 69-89. 2014.

OLIVEIRA, R. M. M. A. de; PASSOS, C. L. B. Promovendo o desenvolvimento profissional na formação de professores: a produção de histórias infantis com conteúdo matemático. Ciência e Educação, Bauru, v. 14, n. 2, p. 315-330, 2008.

ONUCHIC, L. R. Uma aula visando o ensino-aprendizagem de matemática através da resolução de problemas, 1f. , 1998. Notas de aula. Mimeografado.

Ensino-aprendizagem de matemática através da resolução de problemas. In: BICUDO, M. A. V. (Org.). Pesquisa em educação matemática: concepções e perspectivas. São Paulo: Editora da UNESP, cap. 12. p. 199-200. 1999.

PASSOS, C. L. B; ANDRADE, J. A. A. O trabalho "com" o professor: cooperação e colaboração. In: PASSOS, C. L. B. (Org.). Processos de formação de professores: narrativas, grupo colaborativo e mentoria. São Carlos: EdUFSCar, 2010. (Coleção UAB-UFSCar).

PASSOS, C. L. B; ROMANATTO, M. C. A Matemática na formação de professores dos anos iniciais: aspectos teóricos e metodológicos. São Carlos: EdUFSCar, 2010. (Coleção UAB-UFSCar).

PLACCO, V. M. N. de S.; SOUZA, V. L. T. de. (Org.). Aprendizagem do adulto professor. São Paulo: Loyola, 2006.
PONTE, J. P. Mathematics teacher's professional knowledge. In: PONTE, J. P.; MATOS, J. F. (Ed.). Proceedings of $18^{\text {th }}$ PME Conference, Lisboa, v. I, p. 195-210. 1994.

SAVIANI, D. Educação: do senso comum à consciência filosófica. São Paulo: Cortez, 1985.

SERRAZINA, M. de L. A formação contínua de professores em matemática: o conhecimento e a supervisão em sala de aula e a sua influência na alteração das práticas. JIEEM - Jornal Internacional de Estudos em Educação Matemática, Lisboa, v. 2, p. 1-23, 2010.

Reflexão, conhecimento e práticas lectivas em matemática num contexto de reforma curricular no I ciclo. Texto de apoio ao seminário no Programa de estudos de Pós-Graduação da PUC-SP, Revista Quadrante, 1999.

SCHOENFELD, A. H. Por que toda esta agitação acerca da resolução de problemas? In: ABRANTES, P.; LEAL, L. C.; PONTE, J. P. (Org.). Investigar para aprender matemática (textos selecionados). 2. ed. Lisboa: Associação de Professores de Matemática; Projecto MPT, p. 61-72. 1996.

SCHROEDER, T. L.; LESTER Jr., F. K. Developing understanding in Mathematics via problem solving. In: TRAFTON, P. R.; SHULTE, A. P. (Ed.). New Directions for

Elementary School Mathematics. Reston: NCTM, 1989.

STANCANELLI, R. Conhecendo diferentes tipos de problemas. In: SMOLE, K. C. S.; DINIZ, M. I. de S. V. (Org.). Ler, escrever e resolver problemas: habilidades básicas para aprender matemática. Porto Alegre: Artmed, p. 103-120. 2001.

VAN DE WALLE, J. A. Matemática no ensino fundamental: formação de professores e aplicação em sala de aula. Tradução de Paulo Henrique Colonese. 6. ed. Porto Alegre: Artmed, 2009.

VILA, A.; CALLEJO, M. L. Matemática para aprender a pensar: o papel das crenças na resolução de problemas. Porto Alegre: Artmed, 2006. 